\title{
Interfacial Bonding of Plasma-coated Hydroxyapatite on Titanium and Ti-6Al-4V
}

\author{
${ }^{1}$ Ravindra Kotian, ${ }^{2}$ Prasad Rao, ${ }^{3}$ Prashanthi Madhyastha
}

\section{ABSTRACT}

Aim: The study aimed to understand the interfacial bonding and diffusion of elements between substrate metal and HAcoated titanium implants in different plasma gas atmosphere.

Materials and methods: Commercially pure titanium and Ti-6Al-4V substrate metals were coated with hydroxyapatite by plasma spray in plasma gas atmospheres of argon, argon/ hydrogen, nitrogen, and nitrogen/hydrogen. The microstructure and interfacial bonding between the metal substrate and HA coating were studied by scanning electron microscopy, energy dispensive X-ray analysis (EDAX), and X-ray diffraction.

Results: The analyses of the coatings obtained showed a different microstructural pattern of $\mathrm{HA}$ and diffusion of elements across the interface of metal and HA coating and chemical bonding for all plasma gas atmospheres.

Conclusion: The plasma-coating atmosphere influences the microstructure and crystallization of HA. Diffusion of elements from metal substrate to HA coating and coating to metal surface indicate chemical bonding between the metal and coating in addition to usual mechanical bonding.

Clinical significance: Bonding between the metal substrate and HA coating play a significant role in the stability of the dental implant. In addition to mechanical bonding, the plasma coated implants show some amount of chemical bonding at the interface.

Keywords: Diffusion, Energy dispensive X-ray analysis, Hydroxyapatite, Interfacial bonding plasma coating, Titanium, $\mathrm{X}$-ray diffraction.

How to cite this article: Kotian R, Rao P, Madhyastha $\mathrm{P}$. Interfacial bonding of plasma coated hydroxyapatite on Titanium and Ti-6AI-4V. World J Dent 2018;9(6):444-450.

\section{Source of support: Nil}

Conflict of interest: None

\section{INTRODUCTION}

Commercially pure titanium and Ti-6Al-4V are the most common metallic materials that are used as implants in medical and dental applications. They show excellent

\footnotetext{
${ }^{1,3}$ Department of Dental Materials, Manipal College of Dental Sciences, Manipal Academy of Higher Education, Mangaluru, Karnataka, India

${ }^{2}$ Department of Metallurgical and Materials Engineering, National Institute of Technology, Mangaluru, Karnataka, India

Corresponding Author: Ravindra Kotian, Department of Dental Materials, Manipal College of Dental Sciences, Manipal Academy of Higher Education, Mangaluru, Karnataka, India, Phone: +918242428716, e-mail: ravindra.kotian@manipal.edu
}

corrosion resistance and mechanical properties. ${ }^{1}$ These metallic materials are coated with bioactive hydroxyapatite (HA) having formulation $\mathrm{Ca}_{10}\left(\mathrm{PO}_{4}\right)_{6}(\mathrm{OH})_{2}$ to chemically link metal/alloy implant and bone. The HA has similar calcium and phosphate minerals found in the bone helping in promoting osteointegration through the formation of a strong bond with the bone.

Plasma spraying ${ }^{1-3}$ is the commonly used surface treatment process for coating HA on substrate metals. The HA coating for medical and dental implants must have strong bond both with substrate metal and bone, appropriate porosity, a high degree of purity and phase stability. ${ }^{4,5}$ The plasma working gas composition remains the same during the plasma spray process which is not a basic parameter that is changed during the coating process. However, it is considered to be an important parameter that influences coating properties. ${ }^{6}$ For example, a mixture of argon and hydrogen as the plasma gas atmosphere gives a suitable coating. However, when only argon gas used as plasma gas, the powder particles tend to rebound from the flame because of its high viscosity and velocity. Plasma gas composition influences the thickness of a coating. For example, nitrogen as plasma gas results in thicker coating compared to the use of argon gas. Therefore, one can expect the possibility of plasma gas composition having a significant role in the properties of HA coating.

Common problems associated with plasma spray process are the micro-crack formation and change composition due to the high temperature of the process, weak bonding between coating and substrate, change in the microstructure, and non-uniformity in the coating density, which fail the implanted structure. ${ }^{7-11}$

It was therefore planned to study the effect of plasma working gas composition on microstructure and interfacial bonding between the coating and metal substrate keeping in mind the necessary parameters of the plasma spray technique. The coatings were made on $\mathrm{Ti}$ and Ti-6Al-4V metal substrates. The plasma gas compositions selected in the present study were argon, nitrogen, argon/ hydrogen, and nitrogen/hydrogen.

\section{MATERIALS AND METHODS}

Commercially pure titanium (ASTM B 348 Gr. 1), hereafter called Ti 12 and Ti-6Al-4V (ASTM B 348 Gr. 5), hereafter 
called Ti 31 were obtained as rods of $8 \mathrm{~mm}$ diameter (Mishra Dhatu Nigam Ltd., Hyderabad, Telangana, India) were used as the substrate metal to be coated with hydroxyapatite by plasma spray technique. The dimension of the substrate metal coated with HA is $100 \mathrm{~mm} \times$ $6 \mathrm{~mm} \times 4 \mathrm{~mm}$.

Hydroxyapatite (Plasma Biotal Limited, UK) was sprayed on Ti 12 and Ti 31 metal substrates. As reported by the manufacturer the HA powder contained traces of calcium oxide phosphate and alpha calcium orthophosphate with an average particle size of 30 microns and relative crystallinity of $97 \%$.

In this study, plasma coating, the technique of providing a protective layer through a plasma spray, was performed at Spraymet Surface Technologies Pvt. Ltd., Bengaluru, India. Three samples each of Ti 12 and $\mathrm{Ti}$ 31 were coated in 4 different types of plasma gas atmospheres of argon (A), argon/hydrogen $(\mathrm{AH})$, nitrogen $(\mathrm{N})$, and nitrogen/hydrogen ( $\mathrm{NH}$ ). Before coating, the surface of the substrate metal was roughened by grit blasting with $\mathrm{Al}_{2} \mathrm{O}_{3}$ of grit size 24 for better bonding between the metal substrate and HA coating. The roughened Ti 12 and Ti 31 samples then washed with water followed by alcohol before plasma coating.

In plasma spray, a direct current was used to generate arc to produce high-temperature ionized plasma jet. The arc was struck between cathode and anode of the torch. The flame was fed with a continuous flow of inert gas, which was ionized by the DC arc. The torch nozzle accelerated the ionized gas with high velocity (more than 800 $\mathrm{m} /$ second) and temperature (12000-16000 K). The powder coating material fed into the ionized stream, where it was heated and thrust towards the substrate. The coating was carried out separately using four gas atmospheres: argon, argon/hydrogen, nitrogen and nitrogen/hydrogen. Here argon and nitrogen served as primary gasses and hydrogen acted as the secondary gas. A pressure
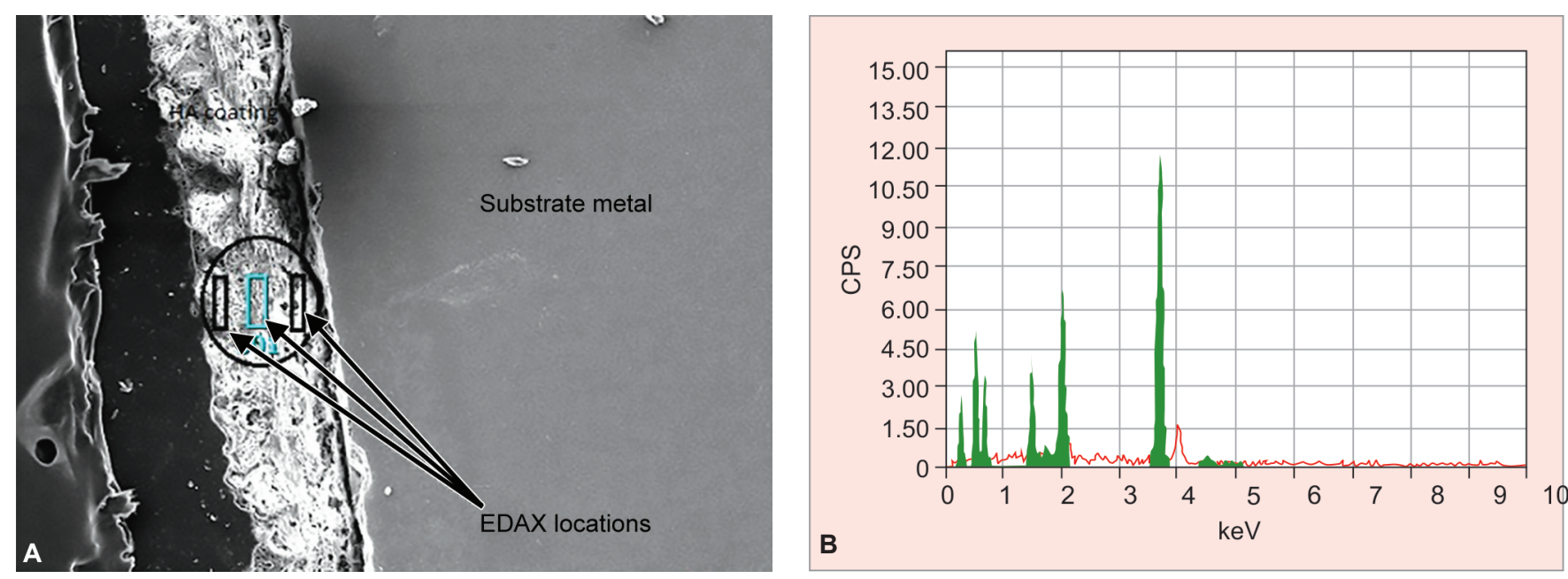

Figs 1A and B: Representative EDAX analysis of diffusion study of Ti 31 under nitrogen/hydrogen 


\section{RESULTS}

Figures 2 and 3 are the SEM micrographs of the HA coating carried out under argon, argon/hydrogen, nitrogen, and nitrogen/hydrogen plasma atmosphere on Ti 12 and Ti 31 substrates.

The HA coating in argon atmosphere showed complex structure composing of tightly adhering particle (Figs 2A and 3A). The coatings made of argon/hydrogen, nitrogen, and nitrogen/hydrogen showed micro-cracks with pancake-like deposits (Figs 2B to D, and 3B to D). The coating appears clean, demonstrating that particles have undergone a crystallization process.

The average diffusion profiles of titanium, vanadium, calcium and phosphorous across the interface are presented in.

The high decomposition of HA and formation of any new phases were studied using X-ray diffraction profiles of HA coatings on Ti 12 and Ti 31 presented in Figure 4. The figure shows the $\mathrm{X}$-ray profile of as received HA and XRD of HA-coated in the different plasma atmosphere.

\section{DISCUSSION}

In plasma spray processing, rapid heating of HA by plasma heat as well as quick cooling by the metal substrate on coating can cause phase transformations of HA crystalline powder. Thus the different thermal history of individual HA particles impacting the titanium substrate at different times generates inhomogeneous microstructure in HA coatings. 12,13
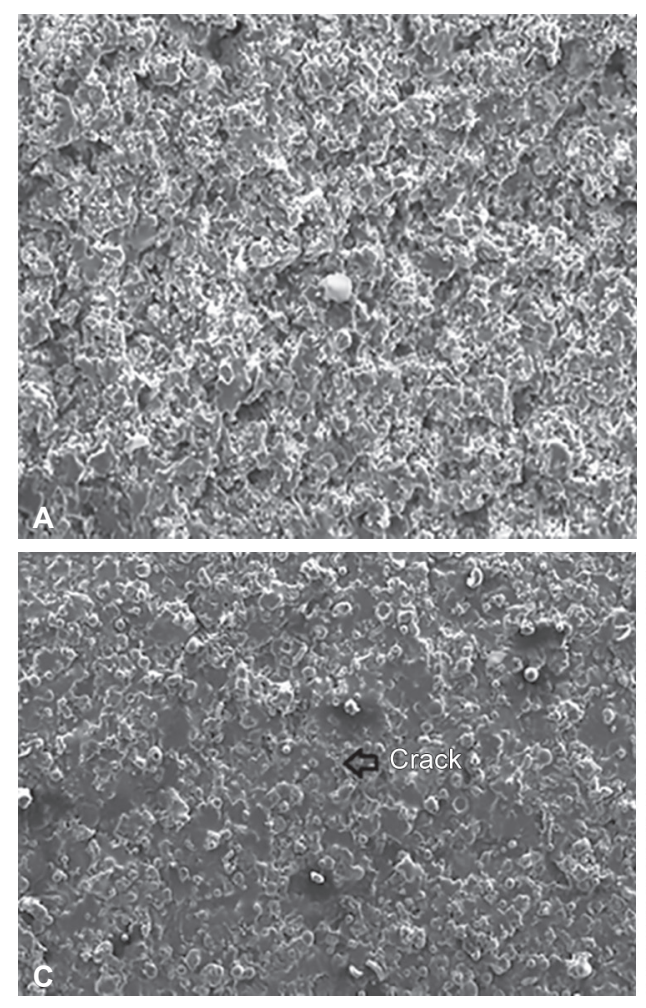

Figs 2A to D: Microstructure of HA coated on Ti 12 in different plasma atmosphere (A) argon; (B) argon/hydrogen,

The argon plasma coated HA showed complex and rough microstructure compared to the microstructures observed in other atmospheres (Figs $2 \mathrm{~A}$ and $3 \mathrm{~A}$ ). In this particular case, it appears that HA particles have not reached sufficiently high fusion temperature compared to other atmospheres. So upon coating and subsequent cooling and coalescence on the substrate, the fused HA droplets have not adequately spread into splat layers because of less fluidity. Instead, the molten HA was confined to the particular region of the coating area. In other atmospheres because of sufficient fusion of HA particles, there was reasonable spreading and coalescence between the splat layers and appear smooth (Figs 2B to D, and 3B to D) for argon/hydrogen, nitrogen, and nitrogen/ hydrogen coatings.

Besides the morphological features, another critical SEM observation was the presence of micro-cracks both on the surface and deeper inside the coatings (Figs 2C and 3C). These micro-cracks observed are attributed to the thermal expansion mismatch between the coating and the substrate.

To understand the nature of interfacial bonding between the metal and HA, the coated samples were studied after sectioning. They were investigated through SEM and EDAX. This was to determine the compositional change taking place during plasma coating. This would help us find out the diffusion of elements from the metal to the coating as well as from the coating to the metal at various depths.
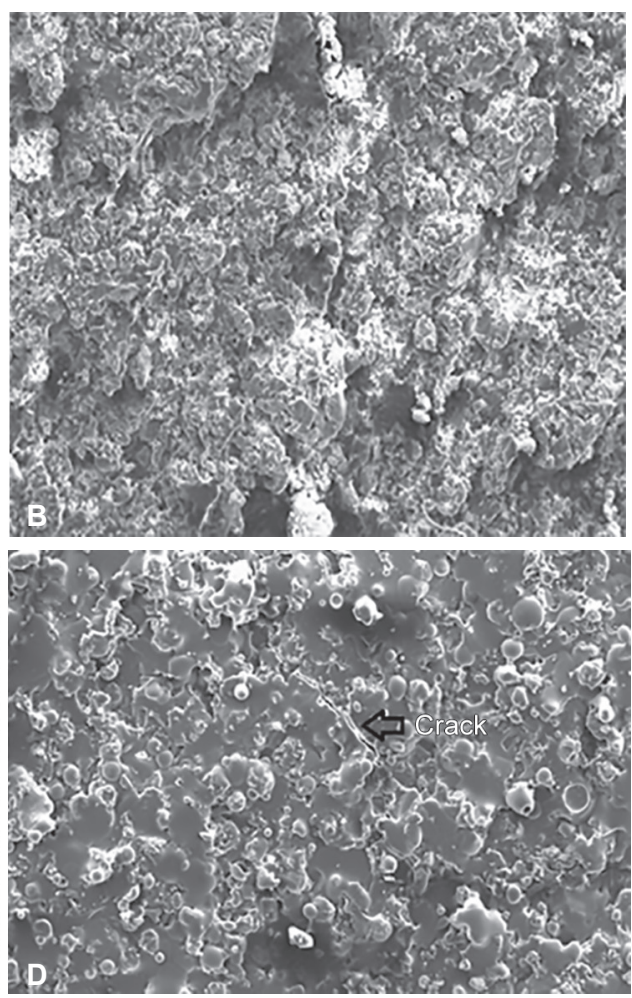

\section{Figs 2A to D: Microstructure of HA coated on Ti 12 in different plasma atmos
(C) nitrogen; (D) nitrogen/hydrogen}



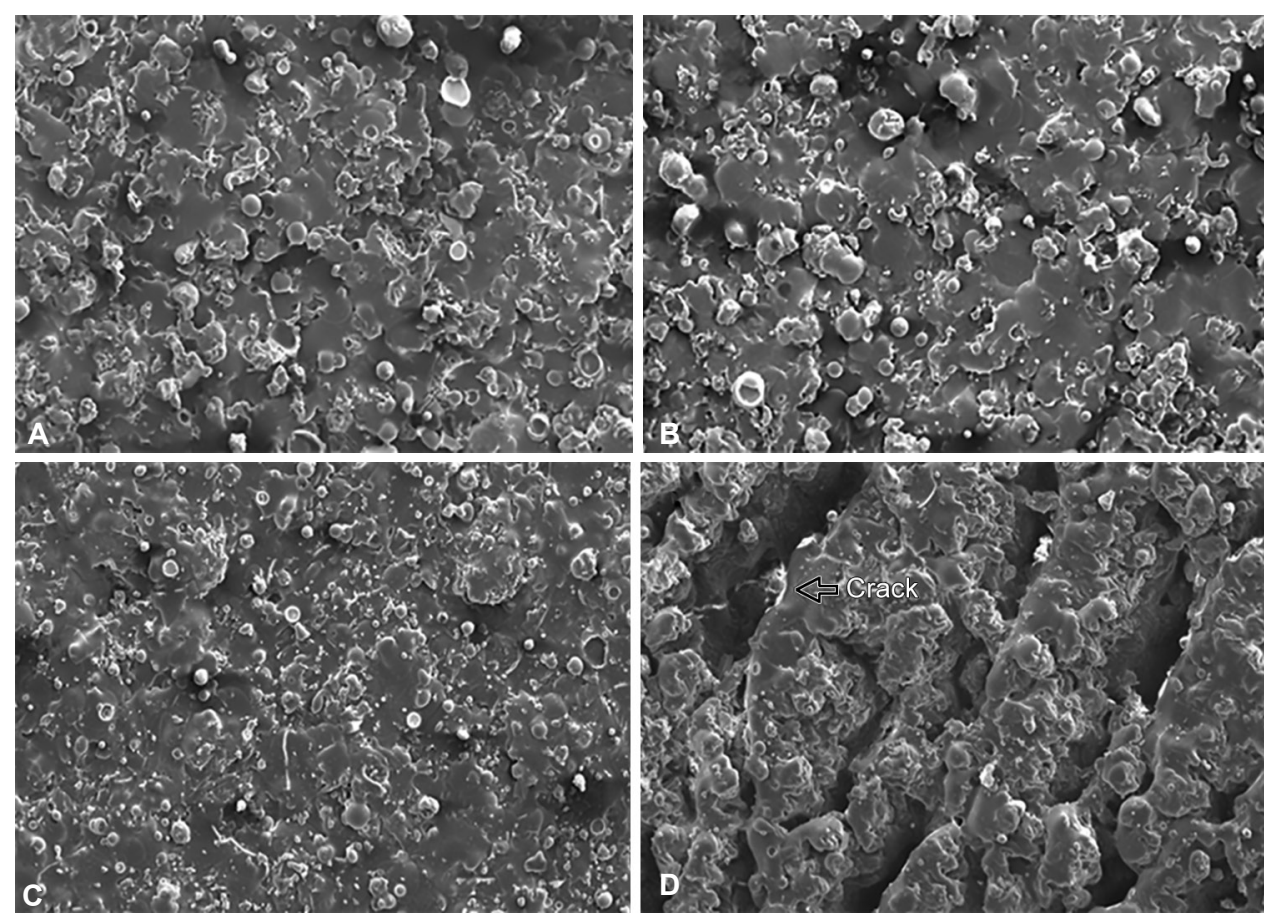

Figs 3A to D: Microstructure of HA coated on Ti 31 in different plasma atmosphere (A) argon; (B) argon/hydrogen; (C) nitrogen; (D) nitrogen/hydrogen
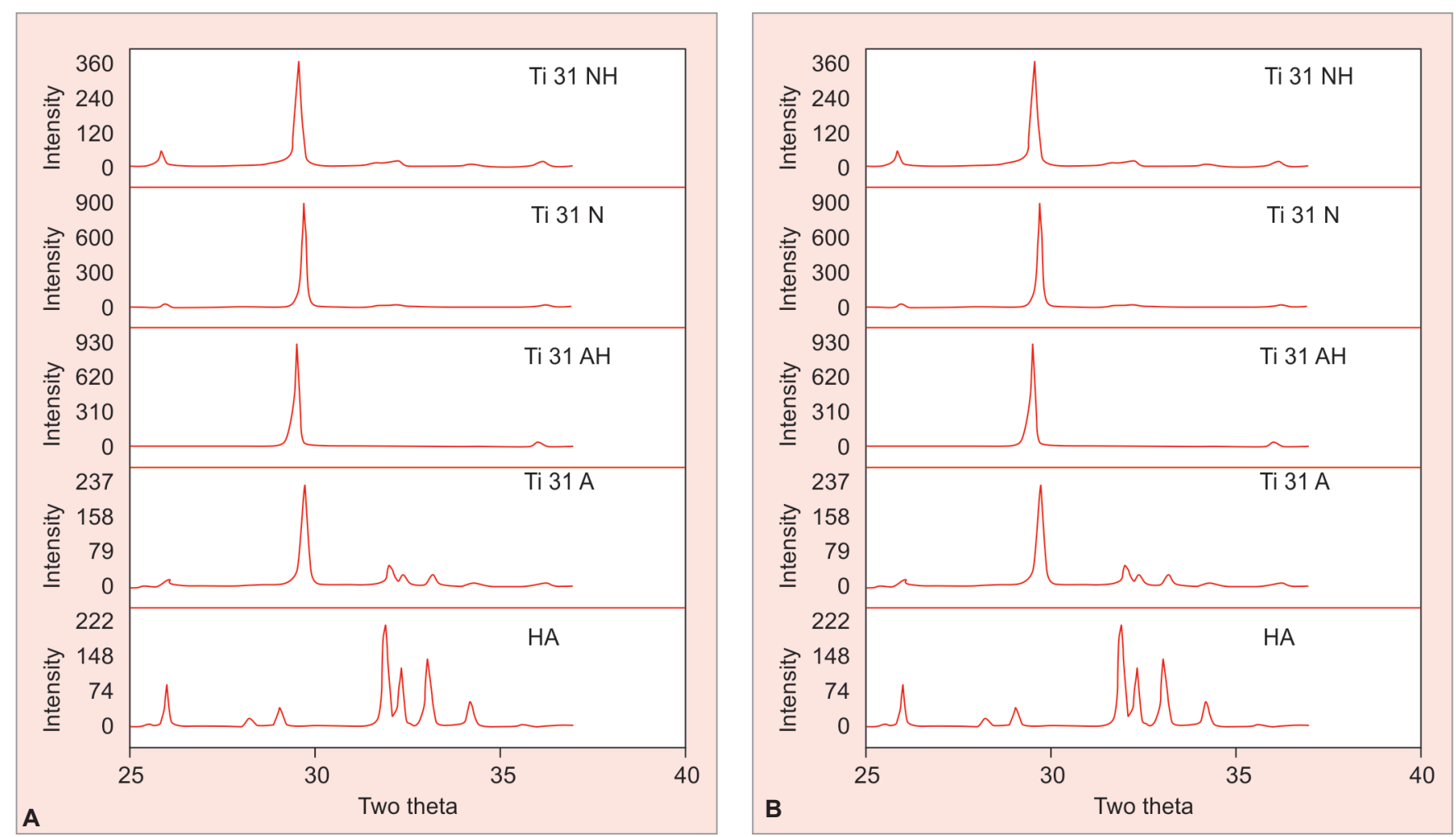

Figs 4A and B: X-ray diffraction pattern of as received $\mathrm{HA}$ and $\mathrm{HA}$-coated on $\mathrm{Ti} 12$ and $\mathrm{Ti} 31$ in the different plasma atmosphere

The diffusion profiles so obtained are presented in Graph 1. From the results, it was found that there was significant mass transfer between the metal and the coating. The diffusion of elements on one side is expected to lead to a corresponding loss on the other side. HA ingredients decreased on either side of the interface for respective constituents as we moved away from the interface.
The energy dispersive analysis (EDAX) showed the presence of calcium, phosphorous, carbon, oxygen, titanium, and aluminum which indicated that this phase was calcium phosphate and with some compounds of titanium and aluminum as shown in Figures 1 and 5. From the diffusion profiles of titanium, vanadium, calcium, and phosphorous it can be seen that there was a mutual mass transfer of 


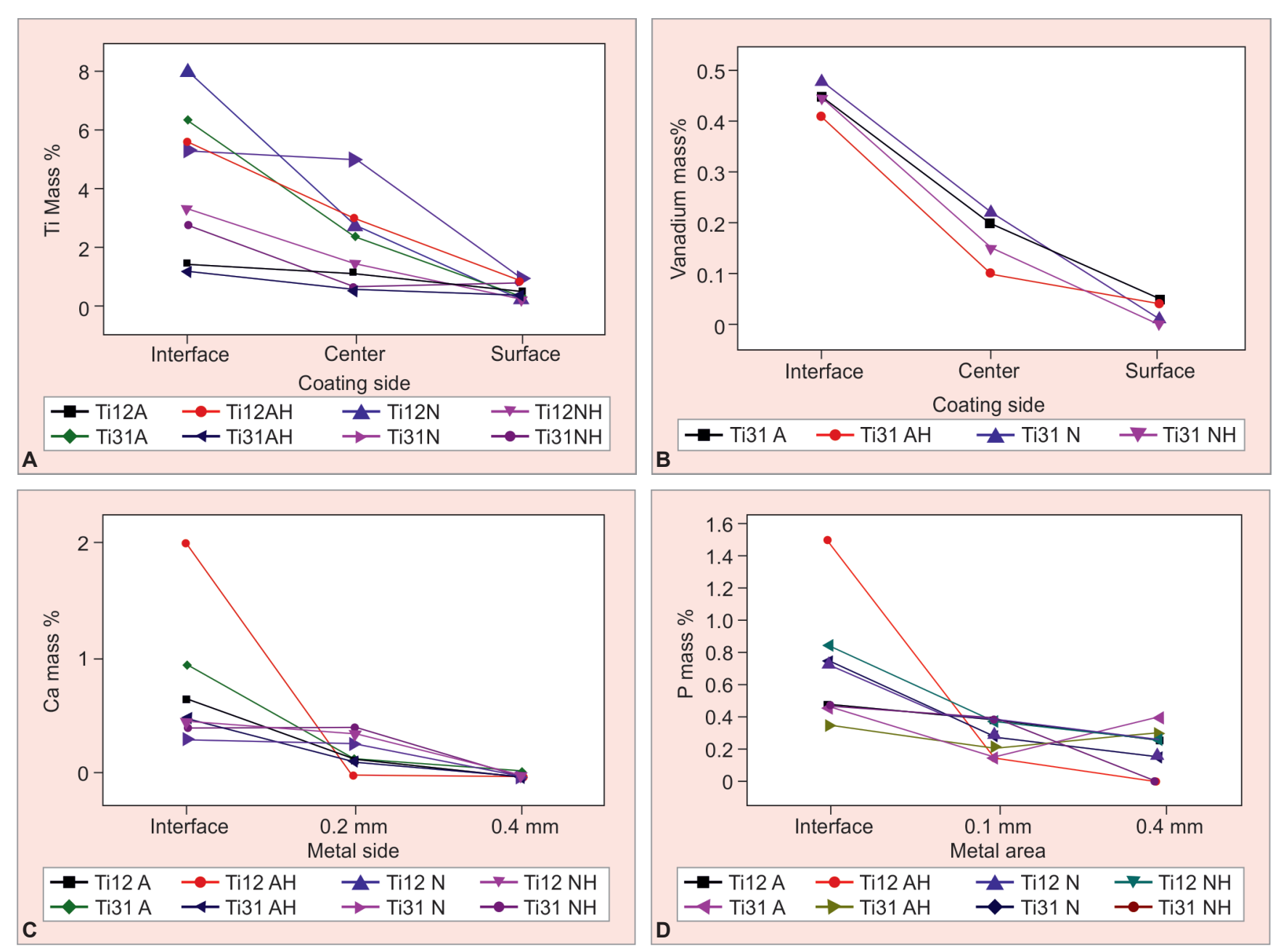

Graphs 1A to D: Diffusion profile of Ti, V, Ca and P
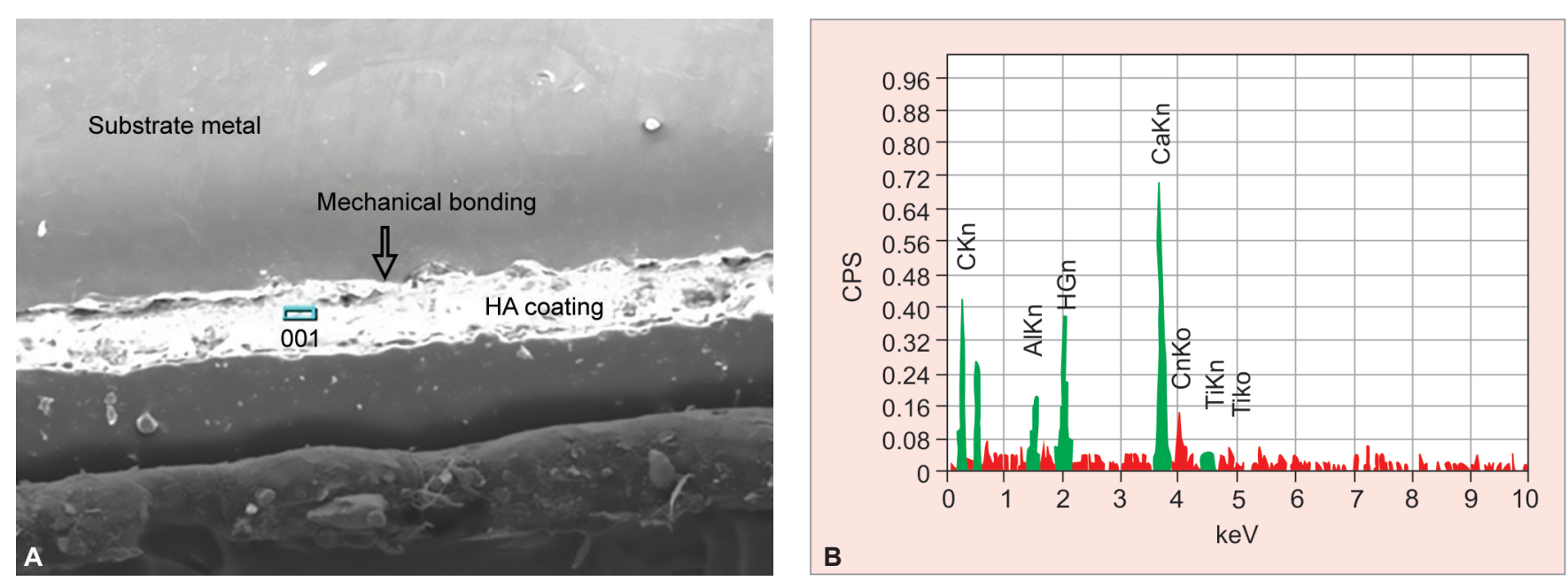

Figs 5A and B: Representative EDAX analysis of diffusion study of Ti 12 under nitrogen/hydrogen

the ingredients between the substrate metal and HA. The diffused mass concentration was found to be more at the interface region, and it decreases on moving away from the interface. The results of these finding are presented in Graph 1. These observations suggest that there was some amount of chemical bonding between the metal and HA coating. This bonding is in addition to the mechanical bonding observed between the metal and HA (Fig. 5).
Variation in the material properties of the HA coating affects the bonding mechanism and rate of bone formation. In-Seop Lee, Chung-Nam Whang, Hyoun-Eee Kim, Jong-Chul Park, Jong Han Song, and Soo-Ryong $\mathrm{Kim}^{14}$ observed that the $\mathrm{Ca} / \mathrm{P}$ ratio of HA coating is an important parameter to determine its dissolution characteristics. They found the HA with high $\mathrm{Ca} / \mathrm{P}$ ratio would promote better bone growth. It was suggested 
that local supersaturation of constituent ions of the bone minerals such as calcium and phosphate arising from ion exchange between the coating surface and surrounding physiological fluid could be the cause of increased bone growth. ${ }^{15-17}$

In the present study, a significant amount of aluminum was also observed during the EDAX analysis, which was more than the expected range. This can be seen in Figures 1 and 4 for Ti 31 and Ti 12. Though Ti 12 does not contain aluminum in its composition, a significant mass percent of 1.54 was seen in the HA coating. In the case, Ti 31 a high aluminum mass percent of 3.86 was observed, which is more than the expected range. This high value of aluminum observed was partly due to the alumina that got embedded at the rough surface of the metal during roughening of the metal substrate by grit blast using $\mathrm{Al}_{2} \mathrm{O}_{3}$ before coating HA for better mechanical bonding. Another source of aluminum is lavigated alumina that was used for polishing the sectioned samples. Some of it might have trapped in the sample in spite of thorough cleaning. So the diffusion profile of aluminum is not presented in the present study. However, aluminum can be expected to diffuse more than vanadium because of the lower fusion temperature of aluminum compared to vanadium.

For the analysis of composition and phases present in HA coatings, the diffraction patterns were analyzed by X'Pert High Score software. The XRD profile of the feedstock shown in Figure 4 was found to be of $\mathrm{Ca}_{10}\left(\mathrm{PO}_{4}\right)_{6}(\mathrm{OH})_{2}$ - calcium phosphate hydroxide, which matched with JCPDS file no. 72-1243. In addition to HA, the XRD profiles of coatings presented in Figure 4 showed the presence of $\beta$ tricalcium phosphate $\left[\mathrm{Ca}_{3}\left(\mathrm{PO}_{4}\right)_{2}\right]$, tetra calcium phosphate $\left[\mathrm{Ca}_{4}\left(\mathrm{PO}_{4}\right) \mathrm{O}\right]$, and $\mathrm{CaO}$. The spectral lines of these compounds matched with JCPDS file no. 9-0169, 70-1379, and 75-0264 respectively. The XRD patterns also showed incorporation of $\mathrm{CO}_{3}{ }^{2-}$ groups into the HA coatings. The HA-coated samples also showed relatively weak diffraction lines for TiH (JCPDS file no. 01-078-2215), $\mathrm{H}_{2}\left[\mathrm{Ti}\left(\mathrm{PO}_{4}\right)_{2}\right]$ (JCPDS 021-0392), $\mathrm{Ca}_{4} \mathrm{Ti}_{3} \mathrm{O}_{10}$ (JCPDS file no. 01-089-1385 and 01-014-0152), $\mathrm{CaV}_{4} \mathrm{O}_{9}$ (01-070-1325), $\mathrm{TiO}_{2}$, and vanadium oxide. These indicate that the metal constituents have chemically reacted with calcium and phosphorous of $\mathrm{HA}$ at high temperature. In the present study, these findings cannot be claimed with certainty as the peaks obtained were very weak. However, there is a possibility of the formation of the compounds as mentioned earlier and is supported by earlier studies as well. ${ }^{18-21}$

\section{CONCLUSION}

The plasma gas composition influences the crystallization, microstructure, and melting of HA coating. Control of the plasma gas temperature is essential to reduce the micro-cracks by thermal stresses.

There is a significant diffusion of HA and substrate metal ingredients across the interface boundary of metal and $\mathrm{HA}$, indicating that there is some amount of chemical bonding between the metal and HA in addition to usual mechanical bonding, Reaction products such as $\mathrm{CaTi}_{3} \mathrm{O}_{4}$, $\mathrm{CaV}_{4} \mathrm{O}_{9}, \mathrm{Ca}_{4} \mathrm{Ti}_{3} \mathrm{O}_{4}$ and $\mathrm{H}_{2}\left[\mathrm{Ti}\left(\mathrm{PO}_{4}\right)_{2}\right]$ formed support chemical bonding between HA and the metal substrate.

\section{CLINICAL SIGNIFICANCE}

Stability of the implant depends on the bonding between the metal substrate and HA coating. In addition to mechanical bonding between HA and metal substrate, the plasma coated implant show some amount of chemical bonding at the interface providing additional bonding.

\section{REFERENCES}

1. Breme J, Schulte W, Donath K. Development of endosseous implants on the base titanium alloys with improved functionality. In: Froes FH, Caplan IL, editors. The Minerals, Metals and Materials Society, Titanium 92 Science and Technology. San Diego, California;1992:2757-2764.

2. Daryl Crawmer. Thermal spray processes. In: Davis JR, editor. Hand Book of Thermal Spray Technology. ASM International and the Thermal Spray Society; 2004:54-76.

3. Ramnarayan Chattopadhya. Plasma Assisted Thermal Processes, Advanced Thermally Assisted Surface Engineering Processes. Kluwer Academic, 2004:50-115.

4. Salsbury RL. Quality control of hydroxyapatite coating: Purity and crystalline determinations. In: Bernecki TF, editor. National Thermal Spray Conf. ASM Int., 1991:471-473.

5. Sun L, Berndt CC, Khor KA, Cheang PA, Gross KA. Surface Characteristics and Dissolution Behavior of Plasma Sprayed Hydroxyapatite Coating. J. Biomed. Mater. Res 2002;36:228-236.

6. Michael J, Yaszemski, Debra J, Trantola, et al. Biomaterials in Orthopaedics. Marcel Dekker, Basel, 2004:401-423.

7. Raja KS, Misra M, Paramguru K. Deposition of calcium phosphate coating on nanotubular anodized titanium. Materials Letters. 2005 Jul 1;59(17):2137-2141.

8. Cizek J, Khor KA, Prochazka Z. Influence of spraying conditions on thermal and velocity properties of plasma sprayed hydroxyapatite. Materials Science and Engineering: C. 2007;27(2):340-344

9. Morks MF, Akira Kobayashi. Influence of gas flow rate on the microstructure and mechanical properties of hydroxyapatite coatings fabricated by gas tunnel type plasma spraying. Surface and Coatings Technology 2006;201:2560-2566.

10. Morks MF, Kobayashi A. Effect of gun current on the microstructure and crystallinity of plasma sprayed hydroxyapatite coatings. Applied Surface Science. 2007;253(17):7136-7142.

11. Sun R, Li M, Lu Y, An X. Effect of titanium and titania on chemical characteristics of hydroxyapatite plasma-sprayed into water. Materials Science and Engineering: C. 2006 Jan 1;26(1):28-33.

12. Wen J, Leng $Y$, Chen J, Zhang C. Chemical gradient in plasmasprayed HA coatings. Biomaterials. 2000;21(13):1339-1343. 
13. Tong W, Chen J, Xingdong Z. Amorphorization and recrystallization during plasma spraying of hydroxyapatite. Biomaterials. 1995 Jul 1;16(11):829-832.

14. Lee IS, Whang CN, Kim HE, Park JC, Song JH, Kim SR. Various $\mathrm{Ca} / \mathrm{P}$ ratios of thin calcium phosphate films. Materials Science and Engineering: C. 2002 Oct 1;22(1):15-20.

15. Hench LL. Bioceramics: from concept to clinic. Journal of the american ceramic society. 1991 Jul;74(7):1487-1510.

16. Legeros RZ. Biodegradation and bioresorption of calcium phosphate ceramics. Clinical materials. 1993;14(1):65-88.

17. Suchanek W, Yoshimura M. Processing and properties of hydroxyapatite-based biomaterials for use as hard tissue replacement implants. Journal of Materials Research. 1998;13(1):94-117.
18. Cirilli F, Kaciulius S, Mattogno G, et al. Surface analysis of biocompatible hydroxyapatite coatings on titanium. Nyborg L, Brigg D Olefjort: Wiley, Chichester, 1997, Biomaterials Proceedings ECASIA 97.

19. Hauxia JI, Ponton CB, Marquis PM. Microstructural characterization of hydroxyapatite on titanium. J Mater Sci Mater Med 1992;3:283-287.

20. Ducheyne P, Van Raemdonck W, Heugherbaert JC, Heugherbaert M. Structural analysis of hydroxyapatite coatings on titanium. Biomaterials 1986;7:97-103.

21. Yan L, Leng Y, Weng LT. Characterization of chemical inhomogeneity in plasma-sprayed hydroxyapatite coatings. Biomaterials. 2003;24(15):2585-2592. 